\title{
Viscosities of the Mixtures of 1-Ethyl-3-Methylimidazolium Chloride with Water, Acetonitrile and Glucose: A Molecular Dynamics Simulation and Experimental Study
}

\author{
Ting Chen, Mandan Chidambaram, Zhiping Liu, Berend Smit,* and Alexis T. Bell* \\ Energy Biosciences Institute and Department of Chemical Engineering, University of California, \\ Berkeley, California 94720-1462 \\ Received: November 30, 2009
}

\begin{abstract}
A recently improved ionic liquid force field was used to compute the viscosity for binary and ternary mixtures of 1-ethyl-3-methylimidazolium chloride $([\mathrm{emim}][\mathrm{Cl}])$ with water, acetonitrile, and glucose. For the same systems, experimental viscosity data are provided. The simulation and experimental results were in reasonable agreement. Simulations consistently overestimate the viscosities for the mixtures of [emim][Cl] and glucose while the viscosities of the mixtures of glucose and water are well reproduced. Both experiments and simulations show that the addition of acetonitrile reduces the viscosity of a solution of [emim] [Cl] and glucose by more than an order of magnitude.
\end{abstract}

\section{Introduction}

The conversion of lignocellulosic biomass to fuels is a subject of considerable contemporary interest, since it offers a potential means for reducing the world's dependence on fossil fuels and mitigating the net emission of $\mathrm{CO}_{2}$ into the atmosphere. ${ }^{1-3}$ The refractory character of lignocellulosic biomass, a mixture of lignin, cellulose, and hemicellulose, makes it difficult to process without initial pretreatment. Recent studies ${ }^{4-8}$ have shown that all of the components of biomass are soluble in ionic liquids (ILs), salts that are liquid below $373 \mathrm{~K}$ and are green solvent candidates for a number of applications..$^{9-13}$ The viscosity of such solutions rises rapidly with biomass dissolution, making it difficult to pump such solutions and causing a reduction in mass transfer rates. As a consequence, there is an interest in understanding how the viscosity of ionic liquids change with the dissolution of carbohydrates and what can be done to reduce the viscosity of such solutions by the addition of a cosolvent.

A significant body of work has appeared recently on the modeling and simulation of the thermodynamic properties of ILs $^{14-23}$ and their mixtures. ${ }^{24,25}$ Efforts have also been undertaken to calculate the viscosity of ILs using equilibrium molecular dynamics simulations, ${ }^{26-29}$ nonequilibrium molecular dynamics methods such as periodic perturbation, ${ }^{30}$ and reverse nonequilibrium molecular dynamics. ${ }^{31,32}$ For the most part, these studies have used force fields derived for the calculation of thermodynamics properties but not guaranteed to be correct for the simulation of dynamics properties. For example, Rey-Castro and $\mathrm{Vega}^{27}$ have computed the viscosities of [emim] [Cl] based on a force field developed by Shim et al. ${ }^{33}$ Their computed viscosities are at least an order of magnitude higher than experimental values at different temperatures although the correct Arrhenius relation was reproduced. Equilibrium MD simulations carried out by Bhargava and Balasubramanian on 1,3-dimethylimidazolium chloride $([\mathrm{mmim}][\mathrm{Cl}])$ at $425 \mathrm{~K}$ also resulted in a viscosity that was four times higher than experimental value. ${ }^{26}$ To address this problem Liu et al. ${ }^{34}$ have recently reviewed the subject of force fields used for simulating the dynamic properties of ILs and have proposed an improved

* To whom correspondence should be addressed. E-mail: (B.S.) berend-smit@berkeley.edu; (A.T.B.) bell@cchem.berkeley.edu. united-atom force field for simulating the dynamic properties of 1-alkyl-3-methyl-imidazolium chloride $\left(\left[\mathrm{C}_{n} \mathrm{mim}\right][\mathrm{Cl}], n=\right.$ $1,2,4,6,8)$. To test the reliability of this force field in the context of biomass solubilization, we present equilibrium viscosity simulations, based on the model of Liu et al, and experimental data for $[\mathrm{emim}][\mathrm{Cl}]$ and binary and ternary solutions of $[\mathrm{emim}][\mathrm{Cl}]$ with water, acetonitrile, and glucose.

\section{Model and Simulations Methods}

The united-atom force field developed by Liu et al. ${ }^{34}$ was used to describe [emim][Cl]. The SPC/E model ${ }^{35}$ was used to describe water. This model yields a computed viscosity of 0.67 $\mathrm{cP}$ at $300.2 \mathrm{~K},{ }^{36}$ in good agreement with previous simulations, ${ }^{37,38}$ and a viscosity of $0.73 \mathrm{cP}$ at $293 \mathrm{~K}$. Our model for acetonitrile is based on the 3 -site model ${ }^{39,40}$ with two additional bonded energy parameters, model A with $k_{\mathrm{b}, \mathrm{Me}-\mathrm{C}}=469 \mathrm{kcal} /\left(\mathrm{mol} \cdot \AA^{2}\right)$ and $k_{\mathrm{b}, \mathrm{C}-\mathrm{N}}=427 \mathrm{kcal} /\left(\mathrm{mol} \cdot \AA^{2}\right)$. Simulation of pure acetonitrile at room temperature gives a density of $791 \mathrm{~kg} / \mathrm{m}^{3}$, which is within $1.9 \%$ of the experimental density of $776.7 \mathrm{~kg} / \mathrm{m}$. The computed viscosity for liquid acetonitrile at room temperature is $0.41 \mathrm{cP}$, which can be compared with the value of $0.35 \mathrm{cP}$ obtained in previous simulation work ${ }^{40}$ and an experimental measurement of $0.34 \mathrm{cP} .{ }^{41}$ The glucose molecule was modeled by an all-atom optimized potential for liquid simulations (OPLS) force field for carbohydrates. ${ }^{42}$ As both the OPLS glucose model and SPC/E model are consistent with the Amber-based ionic liquid force field of Liu et al, conventional Lorentz-Berthelot mixing rules were used for cross interactions. All simulation systems contained 200 [emim][Cl] molecules. The number of water, acetonitrile, and glucose molecules varied depending on the specified molar fractions. All MD simulations were performed using $\mathrm{LAMMPS}^{43}$ at $373 \mathrm{~K}$ except for the mixture of $\beta$-glucose and water where simulations were run at $293 \mathrm{~K}$. The time step was 2 fs and the SHAKE algorithm was employed to constrain bonds and angles involving hydrogen. The cutoff distance was $12 \AA$ for both Lennard-Jones (LJ) and Coulombic interactions. Long-range tail corrections for both energy and pressure were applied. A particle-particle particle mesh solver with a precision of $10^{-4}$ was employed to treat long-range electrostatic interactions. PACKMOL ${ }^{44}$ was used to generate the initial state of the system in a large cubic box, followed by 
an energy minimization run of $20 \mathrm{ps}$. The systems were first run for $2-4 \mathrm{~ns}$ in a NPT ensemble at $1 \mathrm{~atm}$ and at the specified temperature, followed by $2-40$ ns NVT simulations to equilibrate the system before the actual $20 \mathrm{~ns}$ production run were carried out. Pressure tensor information was recorded at every time step. In computing time correlation function, we used the multiple-time-origin-average method ${ }^{45}$ to improve the statistic of the viscosity computation the block-averaging method ${ }^{46}$ to estimate the standard deviation in the results. Viscosities were determined using equilibrium molecular dynamics (via the Green Kubo formula ${ }^{36,47,48}$ ). All computations of viscosity converged within 4 ns.

\section{Experimental Section}

[emim] $[\mathrm{Cl}](98 \%)$, glucose, and acetonitrile $\left(\mathrm{CH}_{3} \mathrm{CN}, \mathrm{HPLC}\right.$ grade) were obtained from Sigma-Aldrich, Fisher Scientific, and Across Chemicals, respectively. [emim][Cl] and glucose were dried under vacuum $(-30 \mathrm{mmHg})$ overnight at 383 and $373 \mathrm{~K}$, respectively, prior to each experiment. From the dried [emim] [Cl], $6 \mathrm{~g}$ was used for viscosity measurements, which were made using a Brookfield Engineering Viscometer (DV-II+ Pro). The temperature of the sample was selected and controlled by a Brookfield Thermosel and temperature controller, respectively. All the samples were measured using the RTD probe and SC4 spindle. The lowest possible shear rate (corresponding to a rotational speed of $3 \mathrm{rpm}$ ) was used in order to measure viscosities at close to zero shear rate, since the simulated viscosities were obtained at this condition. The error in the viscosity measurements of [emim] $[\mathrm{Cl}],[\mathrm{emim}][\mathrm{Cl}]$ - water, and [emim] $[\mathrm{Cl}]-$ glucose was $\pm 0.5 \mathrm{cP}$, and for the [emim] $[\mathrm{Cl}]-$ acetonitrile and $[\mathrm{emim}][\mathrm{Cl}]-$ glucose-acetonitrile the error was -1 to $-3 \mathrm{cP}$ (depending upon the concentration of acetonitrile, i.e., the more acetonitrile the higher the error) since acetonitrile evaporates rapidly at the temperature of the experiments. The error is exclusively negative, since the viscosity decreases with higher concentration of acetonitrile. The accuracy of the viscometer was checked by using the reference liquid provided with the viscometer. Viscosities of the samples containing acetonitrile were measured rapidly once the required temperature had been reached to minimize the loss of acetonitrile due to evaporation. Since the boiling point of acetonitrile is $359 \mathrm{~K}$, $[\mathrm{emim}][\mathrm{Cl}]$ and acetonitrile were mixed at $353 \mathrm{~K}$ and transferred into the RTD probe, which had been preheated to $373 \mathrm{~K}$. This procedure gave $1 \mathrm{~min}$ for the mixture to reach $373 \mathrm{~K}$ (monitored by temperature sensor on viscometer) and for the measurement of the viscosity. After $1.5 \mathrm{~min}$, the loss of acetonitrile was observed due to evaporation became significant.

\section{Results and Discussion}

Figure 1 and Table 1 compare the computed viscosities for pure $[\mathrm{emim}][\mathrm{Cl}]$ with those measured in the present study and those reported earlier by Seddon et al. ${ }^{49}$ While the computed viscosities are $20-50 \%$ higher than those observed experimentally, the predicted dependence of viscosity on temperature agrees closely with that observed experimentally.

A known experimental difficulty is that once exposed to the air, ILs can absorb water vapor, leading to a decrease in the viscosity of the IL. Figure 2 shows the computed viscosity for mixtures of $[\mathrm{emim}][\mathrm{Cl}]$ and water as a function of the mole fraction of water. Table 2 lists the simulated viscosity and density values along with the corresponding experimental data. As expected, the viscosity decreases as the water content increases, and a good agreement is seen between the computed and experimentally measured viscosities.

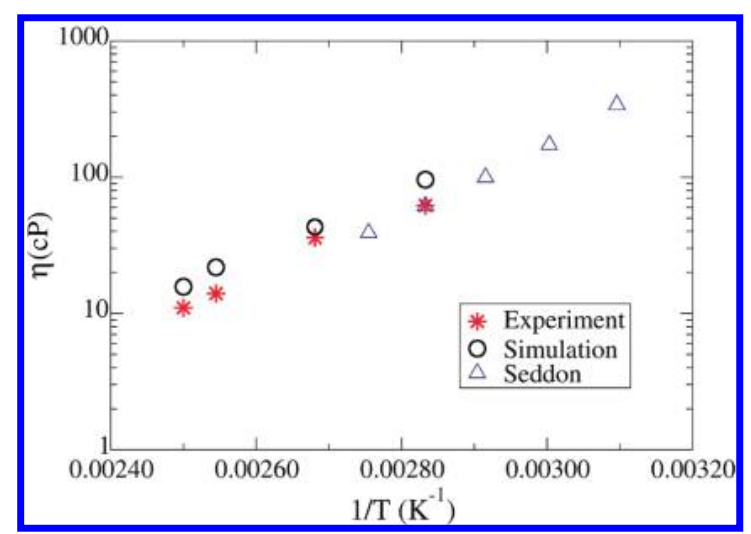

Figure 1. Viscosity of pure $[\mathrm{emim}][\mathrm{Cl}]$ as a function of temperature. Experimental conditions: $[\mathrm{emim}][\mathrm{Cl}](6.0 \mathrm{~g})$; shear rate $(3 \mathrm{rpm})$; measurement time $(5-10 \mathrm{~s})$.

TABLE 1: Computed Viscosities for Pure [emim][Cl] As a Function of Temperature ${ }^{a}$

\begin{tabular}{ccc}
\hline$T / \mathrm{K}$ & $\eta_{\text {sim }}(\mathrm{cP})$ & $\eta_{\exp }(\mathrm{cP})$ \\
\hline 353 & $96 \pm 5$ & 62 \\
373 & $43 \pm 6$ & 36 \\
393 & $21.8 \pm 1.3$ & 14 \\
400 & $15.7 \pm 1.3$ & 11 \\
420 & $10.5 \pm 1.6$ & 9
\end{tabular}

${ }^{a}$ Experimental conditions: [emim] [Cl] $(6.0 \mathrm{~g})$; shear rate $(3 \mathrm{rpm})$; measurement Time $(5-10 \mathrm{~s})$.

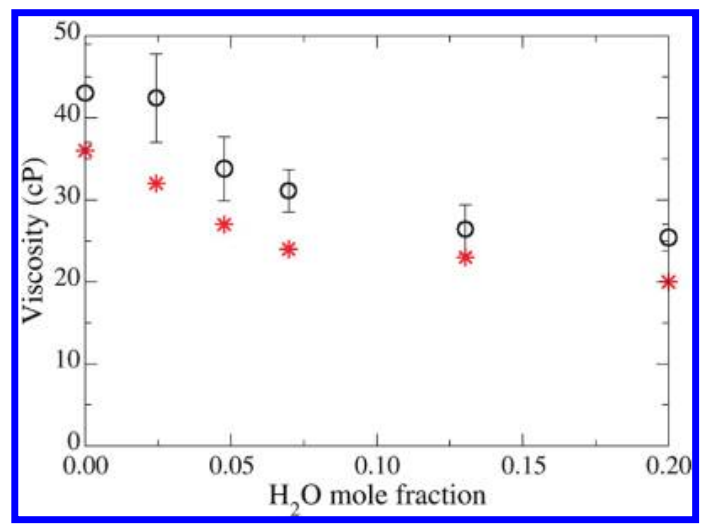

Figure 2. Viscosities of water-[emim $][\mathrm{Cl}]$ solutions at $373 \mathrm{~K}$. Experimental condition: [emim] [Cl] $(6.0 \mathrm{~g})$; water $(0.0,0.018,0.037$, $0.055,0.110,0.184 \mathrm{~g})$; temperature $(373 \mathrm{~K})$; shear rate $(3 \mathrm{rpm})$; measurement time $(5-10 \mathrm{~s})$.

The influence of acetonitrile on the viscosity of ILs is important from a practical point of view. Figure 3 shows the experimental and computed viscosity values for the mixture of [emim] $[\mathrm{Cl}]$ and acetonitrile at different mole fractions of acetonitrile. Table 3 lists the corresponding viscosities and densities. Reference to Figure 3 and Table 3 shows that the experimentally measured viscosities are higher than those computed. The reason for this discrepancy could be the loss of acetonitrile due to evaporation. To minimize the influence of the possible loss of acetonitrile on the viscosity measurement for such mixtures, experiments were made with respect to measurement time and were extrapolated to zero time. It is noteworthy that if the maximum error limits (see Experimental Section) are subtracted from the experimentally observed viscosities, the experimental viscosities become lower than or equal to the computed viscosities. Figure 3 shows a fit of the experimental data to an empirical, cube-root formula proposed originally by Kendall and Monroe ${ }^{50}$ for solutions of benzene and toluene with benzyl benzoate and ethyl benzoate 


$$
\eta_{\text {mix }}^{1 / 3}=x_{1} \eta_{1}^{1 / 3}+x_{2} \eta_{2}^{1 / 3}
$$

In this equation $\eta_{\text {mix }}$ is the viscosity of the mixture, $\eta_{1}$ and $\eta_{2}$ are the viscosities of pure [emim] $[\mathrm{Cl}]$ and acetonitrile, respectively; and $x_{1}$ and $x_{2}$ and are the corresponding mole fractions. Since we were unable to measure the viscosity of pure acetonitrile at $373 \mathrm{~K}$ (acetonitrile boils at this temperature), we used the simulated value $(0.214 \mathrm{cP})$ for $\eta_{2}$ in eq 1 . Also shown in Figure 3 is a fit of the simulated viscosity to a logarithmic formula first proposed by Arrhenius ${ }^{50-52}$

$$
\ln \eta_{\text {mix }}=x_{1} \ln \eta_{1}+x_{2} \ln \eta_{2}
$$

Both eqs 1 and 2 are empirical equations and are referred to as "ideal mixing" models in the literature, since they do not contain cross interaction parameters. ${ }^{31}$ We notice that both computed and experimentally measured viscosities lie between the cube root mixing rule and the Arrhenius mixing law. It has been shown in the literature that mixing rules, such as eqs 1 and 2 , are unable to properly describe the viscosity-composition relationship for complex systems such as mixtures of heavy oil and $n$-decane,,$^{53}$ and we expect that such simple mixing rules will not hold for solutions involving ILs as well. Nevertheless, an exponential dependence of the viscosity of a solution of an IL with a low viscosity cosolvent has been observed previously ${ }^{54,55}$ For example, Wang et al. ${ }^{55}$ have reported measurements of the viscosity of mixtures of 1- $n$-butyl-3-methylimidazolium tetrafluoroborate ([bmim][BF4]) with four small organic molecules including acetonitrile. It was found that all four cosolvents lowered the viscosity of the IL-co-solvent solution and followed a seemingly universal exponential rela-

TABLE 2: Computed Viscosities and Densities for Water-[emim $][\mathrm{Cl}]$ Solutions As a Function of Water Content at $T=373 \mathrm{~K}^{a}$

\begin{tabular}{lccc}
\hline $\begin{array}{c}\text { water mole } \\
\text { fraction }\end{array}$ & $\eta_{\text {sim }}(\mathrm{cP})$ & $\eta_{\exp }(\mathrm{cP})$ & $\rho_{\text {sim }}\left(\mathrm{kg} / \mathrm{m}^{3}\right)$ \\
\hline 0 & $43 \pm 6$ & 36 & 1094.4 \\
0.0244 & $36.5 \pm 0.7$ & 32 & 1094.1 \\
0.0476 & $33.8 \pm 3.9$ & 27 & 1094.1 \\
0.0698 & $31.1 \pm 2.6$ & 24 & 1097.2 \\
0.13 & $26.4 \pm 3$ & 23 & 1096.3 \\
0.2 & $25.4 \pm 1.6$ & 20 & 1103.4
\end{tabular}

${ }^{a}$ Experimental condition: [emim] $[\mathrm{Cl}](6.0 \mathrm{~g})$; water $(0.0,0.018$, $0.037,0.055,0.110,0.184 \mathrm{~g})$; temperature $(373 \mathrm{~K})$; shear rate $(3$ rpm); measurement time (5-10 s).

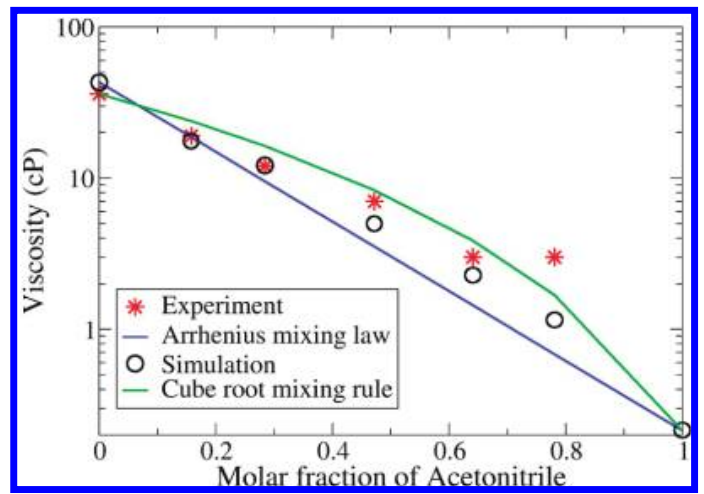

Figure 3. Viscosity of acetonitrile-[emim] [Cl] solutions at $373 \mathrm{~K}$. Experimental condition: $[\mathrm{emim}][\mathrm{Cl}](6.0 \mathrm{~g})$; acetonitrile $(0.0,0.315$, $0.666,1.502,2.999,5.991 \mathrm{~g})$; temperature $(373 \mathrm{~K})$; shear rate $(3 \mathrm{rpm})$; viscosity measurements were done at different times and then extrapolated to zero time.
TABLE 3: Computed Viscosities and Densities for Acetonitrile- $-[$ emim $][\mathrm{Cl}]$ Solution As a Function of Acetonitrile Content at $373 \mathrm{~K}^{a}$

\begin{tabular}{cccc}
\hline $\begin{array}{c}\mathrm{CH}_{3} \mathrm{CN} \text { mole } \\
\text { fraction }\end{array}$ & $\eta_{\text {sim }}(\mathrm{cP})$ & $\eta_{\exp }(\mathrm{cP})$ & $\rho_{\text {sim }}\left(\mathrm{kg} / \mathrm{m}^{3}\right)$ \\
\hline 0 & $43 \pm 6$ & 36 & 1094.4 \\
0.158 & $17.5 \pm 1$ & 19 & 1071.5 \\
0.284 & $12.15 \pm 0.27$ & 12 & 1049.5 \\
0.472 & $4.86 \pm 0.27$ & 7 & 1008.0 \\
0.641 & $2.27 \pm 0.15$ & 3 & 959.5 \\
0.781 & $1.15 \pm 0.1$ & 3 & 899.6 \\
1 & $0.214 \pm 0.004$ & N/A & 719.8
\end{tabular}

${ }^{a}$ Experimental condition: [emim][Cl] $(6.0 \mathrm{~g})$; acetonitrile $(0.0$, $0.315,0.666,1.502,2.999,5.991 \mathrm{~g})$; temperature $(373 \mathrm{~K})$; shear rate (3 rpm); viscosity measurements were done at different times and then extrapolated to zero time.

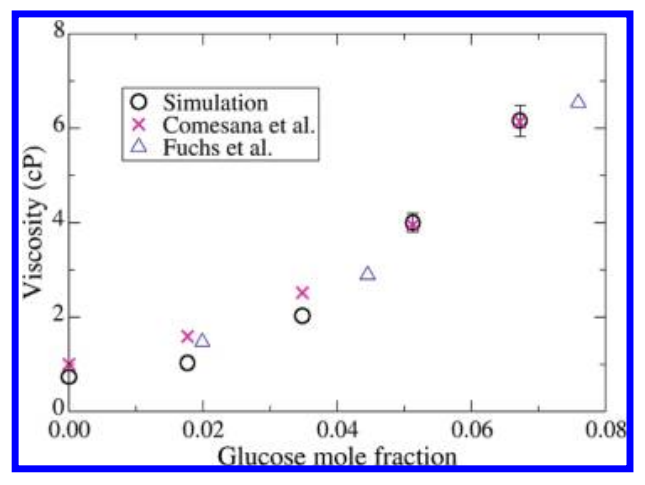

Figure 4. Viscosity of glucose-water solution at $293 \mathrm{~K}$ as a function of glucose mole fraction. Open circles are our simulation data while crosses and triangles are experimental data taken from refs 56 and 57, respectively.

TABLE 4: Computed Viscosities and Densities for the Glucose-Water Solutions As a Function of Glucose Concentration at $T=293 \mathrm{~K}^{a}$

\begin{tabular}{lccccc}
\hline $\begin{array}{c}\text { glucose mole } \\
\text { fraction }\end{array}$ & $c /\left(\mathrm{mol}_{\mathrm{kg}} \mathrm{kg}^{-1}\right)$ & $\eta_{\text {sim }}(\mathrm{cP})$ & $\eta_{\exp }(\mathrm{cP})$ & $\rho_{\text {sim }}\left(\mathrm{kg} / \mathrm{m}^{3}\right)$ & $\rho_{\text {exp }}\left(\mathrm{kg} / \mathrm{m}^{3}\right)$ \\
\hline 0 & 0 & $0.73 \pm 0.01$ & 1 & 997.6 & 998.2 \\
0.0177 & 1 & $1.03 \pm 0.03$ & 1.587 & 1059.2 & 1060 \\
0.0348 & 2 & $2.03 \pm 0.11$ & 2.512 & 1105.55 & 1109 \\
0.0513 & 3 & $4.0 \pm 0.2$ & 3.947 & 1142.5 & 1149 \\
0.0672 & 4 & $6.16 \pm 0.33$ & 6.131 & 1176.4 & 1182
\end{tabular}

${ }^{a}$ The experimental data are taken from ref 57.

tionship, $\eta_{\text {mix }}=\eta_{1} \exp \left(-x_{2} / a\right)$, in which $a=0.216$. If eq 2 is used to fit the data shown in Figure 3, a value of $a=0.19$ is obtained, in good agreement with that obtained by Wang et al.. A fit of the simulated viscosities shown in Figure 3 reveals that the simulation data closely follow an exponential relationship well except for the last data point for liquid acetonitrile, which lies below the trend line.

In the context of carbohydrate processing, there is considerable practical interest in understanding the influence of dissolved carbohydrates on the viscosity of carbohydrate-IL solutions. A first step in this direction is to investigate the effect of dissolved glucose on the solution viscosity. As a check of the OPLS force field for carbohydrates, simulations were carried out for glucose-water mixtures at $293 \mathrm{~K}$. The results are presented in Figure 4 and Table 4 . As can be seen, the agreement between the simulated and measured densities is excellent, the deviation amounting to only $0.3 \%$ on average. Since the SPC/E model of water estimates the viscosity of pure water as 0.73 $\mathrm{cP}$, compared to the experimental value of $1 \mathrm{cP}$ at $293 \mathrm{~K}$, the computed viscosities for the mixtures are slightly smaller than experimental values. Overall, the computed viscosities match 


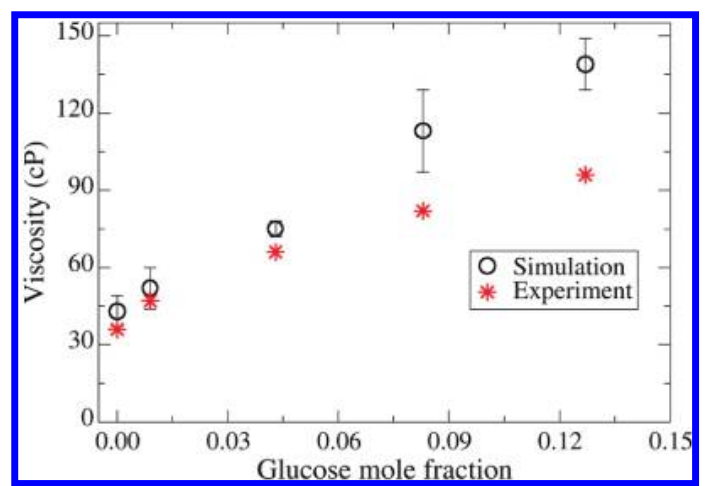

Figure 5. Viscosities of glucose-[emim] $[\mathrm{Cl}]$ solutions at $T=373 \mathrm{~K}$ as a function of glucose mole fraction. Experimental condition: $[\mathrm{emim}][\mathrm{Cl}](6.0 \mathrm{~g})$; glucose $(0.0,0.062,0.320,0.670,1.060 \mathrm{~g})$; temperature $(373 \mathrm{~K})$; shear rate $(3 \mathrm{rpm})$; measurement time $(5-10 \mathrm{~s})$.

TABLE 5: Computed Viscosities for the

Glucose $-[\mathrm{emim}][\mathrm{Cl}]$ Solutions and the Ternary Solutions of Glucose, [emim] [Cl], and Acetonitrile at $373 \mathrm{~K}^{a}$

\begin{tabular}{cccccc}
\hline $\begin{array}{c}\text { glucose mole } \\
\text { fraction }\end{array}$ & $\begin{array}{c}\eta_{\text {sim }} \\
(\mathrm{cP})\end{array}$ & $\begin{array}{c}\eta_{\exp } \\
(\mathrm{cP})\end{array}$ & $\begin{array}{c}\text { glucose mole } \\
\text { fraction }\end{array}$ & $\begin{array}{c}\eta_{\text {sim }}(\mathrm{cP}) \\
\text { with } \mathrm{CH}_{3} \mathrm{CN}\end{array}$ & $\begin{array}{c}\eta_{\text {exp }}(\mathrm{cP}) \\
\text { with } \mathrm{CH}_{3} \mathrm{CN}\end{array}$ \\
\hline 0 & $43 \pm 6$ & 36 & 0 & $2.27 \pm 0.15$ & 3 \\
0.009 & $52 \pm 8$ & 47 & 0.0036 & $2.3 \pm 0.05$ & 3 \\
0.043 & $75 \pm 3$ & 66 & 0.0159 & $3 \pm 0.2$ & 4 \\
0.083 & $113 \pm 16$ & 82 & 0.0313 & $4.5 \pm 0.4$ & 5 \\
0.126 & $139 \pm 10$ & 96 & 0.0495 & $5.38 \pm 0.96$ & 6
\end{tabular}

${ }^{a}$ Experimental condition: [emim] [Cl] $(6.0 \mathrm{~g})$; glucose $(0.0,0.062$, $0.320,0.670,1.060 \mathrm{~g})$; acetonitrile $(3.0 \mathrm{~g})$; temperature $(373 \mathrm{~K})$; shear rate $(3 \mathrm{rpm})$; measurement time $(5-10 \mathrm{~s})$.

very well with the two sets of experimental measurements reported in the literature. ${ }^{56,57}$ These tests demonstrate that the density and viscosity of glucose-water solution are predicted well by the all-atom OPLS carbohydrate force field ${ }^{42}$ in combination with the SPC/E model of water.

Figure 5 and Table 5 compare the simulated and experimentally measured viscosities of solutions of glucose in [emim] $[\mathrm{Cl}]$. The simulations consistently overestimate the viscosity for these mixtures. This is expected since even for pure [emim] $[\mathrm{Cl}]$ the current force field overestimate the viscosity of $[\mathrm{emim}][\mathrm{Cl}]$ by $20-50 \%$ as compared to those determined experimentally (see Figure 1). Nevertheless, the simulations capture the qualitative trend observed experimentally that viscosity increases as glucose concentration increases.

In experiments, we found that adding $3 \mathrm{~g} \mathrm{CH}_{3} \mathrm{CN}$ to the mixtures of $6 \mathrm{~g}[\mathrm{emim}][\mathrm{Cl}]$ and varying amount of glucoses lowered the viscosity of the mixtures by more than an order of magnitude. As shown in Figure 6 and Table 5, the results of experiments and simulations agree well with each other, demonstrating that acetonitrile can be used to lower the viscosity of the solutions of glucose in ILs. Here too it was observed that the experimentally measured viscosity was higher than that computed, as was observed for [emim] $[\mathrm{Cl}]$-acetonitrile mixtures (Figure 3 and Table 3). The reason for the discrepancy could be the same, that is, loss of acetonitrile during the experiment. However, the difference between computed and experimental values is higher for lower glucose concentration and lower for higher glucose concentration.

\section{Conclusions}

Molecular dynamics simulations have been carried out to determine the viscosity of binary and ternary solutions of acetonitrile, glucose, and $[\mathrm{emim}][\mathrm{Cl}]$. The computed and

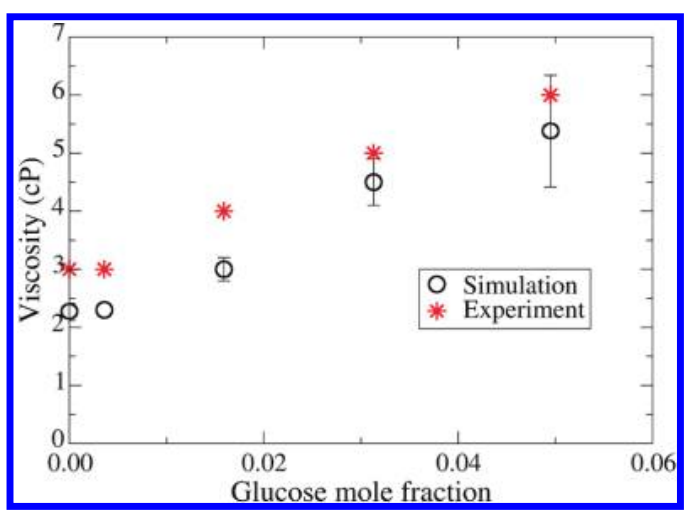

Figure 6. Viscosities of ternary solutions of [emim][Cl], glucose, and acetonitrile at $373 \mathrm{~K}$ as a function of glucose mole fraction. Experimental condition: $[\mathrm{emim}][\mathrm{Cl}](6.0 \mathrm{~g})$; glucose $(0.0,0.062,0.320,0.670$, $1.060 \mathrm{~g})$; acetonitrile $(3.0 \mathrm{~g})$; temperature $(373 \mathrm{~K})$; shear rate $(3 \mathrm{rpm})$; measurement time $(5-10 \mathrm{~s})$.

experimentally measured viscosities for mixtures of [emim] $[\mathrm{Cl}]$ and acetonitrile lie between the Arrhenius mixing rule and a cube root formula, both of which are empirical, "ideal mixing" models. Simulations consistently overestimate the viscosities for solutions of [emim] [Cl] and glucose; however, the viscosities of the glucose and water solutions are well reproduced. Both experiments and simulations also show that the addition of acetonitrile can reduce the viscosity of solutions of [emim] [Cl] and glucose by more than an order of magnitude. In general, simulated viscosities agreed well with our own experimental measurements as well as those reported in the literature.

Acknowledgment. Funding for this work was provided by BP through the Energy Biosciences Institute. The authors thank Sriharsha Jayanti and Sasisankar Padmanabhan for experimental assistance and fruitful discussions, respectively.

\section{References and Notes}

(1) Perlack, R. D.; Wright, L. L.; Turhollow, A. F.; Graham, R. L.; Stokes, B. J.; Erbach, D. C. Biomass as feedstock for a bioenergy and bioproducts industry: The technical feasibility of a billion-ton annual supply; U.S. Department of Commerce: Springfield, VA, 2005.

(2) Facing the Hard Truths about Energy; Council, U. S. N. P., Ed.; National Petroleum Council: Washington DC, 2007.

(3) Chheda, J. N.; Huber, G. W.; Dumesic, J. A. Angew. Chem., Int. Ed. 2007, 46, 7164 .

(4) Swatloski, R. P.; Spear, S. K.; Holbrey, J. D.; Rogers, R. D. J. Am. Chem. Soc. 2002, 124, 4974.

(5) Li, C. Z.; Zhao, Z. K. B. Adv. Svnth. Catal. 2007, 349, 1847.

(6) Li, C. Z.; Wang, Q.; Zhao, Z. K. Green Chem. 2008, 10, 177.

(7) Fukaya, Y.; Hayashi, K.; Wada, M.; Ohno, H. Green Chem. 2008, $10,44$.

(8) Zavrel, M.; Bross, D.; Funke, M.; Buchs, J.; Spiess, A. C. Bioresour. Technol. 2009, 100, 2580.

(9) Huddleston, J. G.; Willauer, H. D.; Swatloski, R. P.; Visser, A. E.; Rogers, R. D. Chem. Commun. 1998, 1765.

(10) Holbrey, J. D.; Seddon, K. R. Clean Prod. Proc. 1999, 1, 223.

(11) Welton, T. Chem. Rev. 1999, 99, 2071.

(12) Parvulescu, V. I.; Hardacre, C. Chem. Rev. 2007, 107, 2615.

(13) Gujar, A. C.; White, M. G.; Dave, C. S. Catalysis 2009, 21, 154.

(14) Liu, Z. P.; Huang, S. P.; Wang, W. C. J.Phvs. Chem. B 2004, $108,12978$.

(15) Urahata, S. M.; Ribeiro, M. C. C. J. Chem. Phvs. 2004, 120, 1855.

(16) Yan, T. Y.; Burnham, C. J.; Del Popolo, M. G.; Voth, G. A. $\underline{\text {. }}$ Phys. Chem. B 2004, 108, 11877.

(17) Cadena, C.; Anthony, J. L.; Shah, J. K.; Morrow, T. I.; Brennecke, J. F.; Maginn, E. J. J. Am. Chem. Soc. 2004, 126, 5300.

(18) Lopes, J. N. C.; Deschamps, J.; Padua, A. A. H. J.Phvs. Chem. B 2004, 108, 2038.

(19) Liu, Z. P.; Wu, X. P.; Wang, W. C. Phvs. Chem. Chem. Phvs. 2006, 8, 1096.

(20) Lopes, J. N. C.; Padua, A. A. H. J.Phvs. Chem. B 2006, 110, 19586. 
(21) Lynden-Bell, R. M.; Del Popolo, M. G.; Youngs, T. G. A.; Kohanoff, J.; Hanke, C. G.; Harper, J. B.; Pinilla, C. C. Acc. Chem. Res. 2007, 40, 1138.

(22) Bhargava, B. L.; Balasubramanian, S. J. Chem. Phvs. 2007, 127, 114510 .

(23) Koddermann, T.; Paschek, D.; Ludwig, R. ChemPhysChem 2007, 8, 2464.

(24) Bhargava, B. L.; Krishna, A. C.; Balasubramanian, S. AIChE J. 2008, 54, 2971.

(25) Wu, X. P.; Liu, Z. P.; Huang, S. P.; Wang, W. C. Phvs. Chem. Chem. Phys. 2005, 7, 2771.

(26) Bhargava, B. L.; Balasubramanian, S. J. Chem. Phvs. 2005, 123, 144505 .

(27) Rey-Castro, C.; Vega, L. F. J. Phvs. Chem. B 2006, 110, 14426.

(28) Rey-Castro, C.; Tormo, A. L.; Vega, L. F. Fluid Phase Equilib. 2007, 256, 62 .

(29) Borodin, O.; Smith, G. D.; Kim, H. J.Phvs. Chem. B 2009, 113, 4771.

(30) Micaelo, N. M.; Baptista, A. M.; Soares, C. M. J. Phvs. Chem. B 2006, $110,14444$.

(31) Kelkar, M. S.; Maginn, E. J. J. Phvs. Chem. B 2007, 111, 4867.

(32) Wei, Z.; Leroy, F.; Balasubramanian, S.; Muller-Plathe, F. J. Phvs. Chem. B 2008, 112, 8129 .

(33) Shim, Y.; Choi, M. Y.; Kim, H. J. J. Chem. Phvs. 2005, 122 044510 .

(34) Liu, Z. P.; Chen, T.; Bell, A. T.; Smit, B. J. Phvs. Chem. B 2010, 114,4572 .

(35) Berendsen, H. J. C.; Grigera, J. R.; Straatsma, T. P. J.Phvs. Chem. 1987, 91, 6269.

(36) Chen, T.; Smit, B.; Bell, A. T. J. Chem. Phvs 2009, 131, 246101.

(37) Hess, B. J. Chem. Phvs. 2002, 116, 209.

(38) Wu, Y. J.; Tepper, H. L.; Voth, G. A. J. Chem. Phvs. 2006, 124, 024503
(39) Edwards, D. M. F.; Madden, P. A.; McDonald, I. R. Mol. Phvs. 1984, $51,1141$.

(40) Mountain, R. D. J. Chem. Phvs. 1997, 107, 3921

(41) Cunningh.Gp; Vidulich, G. A.; Kay, R. L. J. Chem. Eng. Data 1967, 12, 336.

(42) Damm, W.; Frontera, A.; TiradoRives, J.; Jorgensen, W. L. J. Comput. Chem. 1997, 18, 1955.

(43) Plimpton, S. J. Comput. Phvs. 1995, 117, 1.

(44) Martinez, L.; Andrade, R.; Birgin, E. G.; Martinez, J. M. J. Comput. Chem. 2009, 30, 2157.

(45) Frenkel, D.; Smit, B. Understanding Molecular Simulation; Academic Press: San Diego, 2001.

(46) Flyvbjerg, H.; Petersen, H. G. J. Chem. Phvs. 1989, 91, 461

(47) Daivis, P. J.; Evans, D. J. J. Chem. Phvs. 1994, 100, 541.

(48) Mondello, M.; Grest, G. S. J. Chem. Phvs. 1997, 106, 9327.

(49) Seddon, K. R.; Stark, A.; Tepper, M. J. Viscosity and Density of 1-Alkyl-3-methylimidazolium Ionic Liquids. In Clean Solvents: Alternative Media for Chemical Reactions and Processing: Abraham, M. A., Moens,

L., Eds.; American Chemical Society: Washington, DC, 2002; p 34.

(50) Kendall, J.; Monroe, K. P. J. Am. Chem. Soc. 1917, 39, 1787.

(51) Arrhenius, S. Z. Phys. Chem. 1887, 1, 285.

(52) Alexander, D. M.; Moy, D. C. Aust. J. Chem. 1981, 34, 1573. 65.

(53) Barrufet, M. A.; Setiadarma, A. Fluid Phase Equilib. 2003, 213,

(54) Seddon, K. R.; Stark, A.; Torres, M. J. Pure Appl. Chem. 2000, 72,2275 .

(55) Wang, J. J.; Tian, Y.; Zhao, Y.; Zhuo, K. Green Chem. 2003, 5, 618.

(56) Comesana, J. F.; Otero, J. J.; Garcia, E.; Correa, A. J. Chem. Eng. Data 2003, 48, 362.

(57) Fuchs, K.; Kaatze, U. J. Phvs. Chem. B 2001, 105, 2036.

JP911372J 